\title{
MANEJO DE PLANTAS DANINHAS EM BETERRABA COM METAMITRON E SUA PERSISTÊNCIA EM ARGISSOLO ${ }^{(1)}$
}

\author{
ROBERT DEUBER $^{(2)}$; MARIA DO CARMO DE SALVO SOARES NOVO(2) ; \\ PAULO ESPÍNDOLA TRANI ${ }^{(3)}$; RONALDO TAVARES DE ARAÚJO ${ }^{(4)}$; ADEMIR SANTINI( ${ }^{(5)}$
}

\begin{abstract}
RESUMO
O experimento foi realizado no Centro Avançado de Pesquisa Tecnológica do Agronegócio de Frutas (IAC), localizado no município de Jundiaí (SP), em condições usuais de cultivo da beterraba (Beta vulgaris L.) cultivar Tall Top Wonder, em Argissolo Vermelho-Amarelo, distrófico. Os objetivos do experimento foram avaliar a eficácia de metamitron, aplicado em pré-emergência, no controle de plantas daninhas; verificar sua seletividade à cultura, e determinar seu período residual. O experimento foi disposto em blocos ao acaso, com quatro repetições; as parcelas foram divididas em duas partes, sendo uma para a beterraba e outra para o estudo do efeito residual. Foram avaliados os efeitos de doses de metamitron (2,8, 3,5 e 4,2 kg.ha- ${ }^{-1}$ de i.a), mantendo-se duas testemunhas: uma sempre capinada e outra mantida com plantas daninhas até o fim do ciclo. As avaliações do controle das plantas daninhas e da seletividade à cultura foram realizadas aos 28 e 70 dias após a aplicação (DAA) do herbicida. A persistência foi avaliada aos 0, 21, 40 e 70 DAA, em biotestes, com alface (Lactuca sativa L.) cultivar Elisa Crespa como planta-teste. As principais plantas daninhas na área experimental foram: Eleusine indica (L.) Gaertn. (capim-pé-de-galinha), Galinsoga parviflora Cav (picão-branco) e Coronopus didymus (L.) Sm. (mentruz). As doses de metamitron aplicadas não causaram sintomas visíveis de intoxicação à parte aérea das plantas de beterraba. O picão branco e o mentruz foram eficientemente controlados com quaisquer das doses de metamitron. Aos 28 DAA, o capim-pé-de-galinha foi totalmente controlado pelas doses de metamitron aplicadas. Entretanto, aos 70 DAA, somente com as doses de 3,5 e 4,2 kg.ha-1 obteve-se controle eficiente dessa espécie. A atividade residual de metamitron, para as doses de 2,8 e $3,5 \mathrm{~kg}^{-\mathrm{ha}^{-1}}$, foi igual a 70 dias e para $4,2 \mathrm{~kg} \cdot \mathrm{ha}^{-1}$ foi superior a esse período. O controle de plantas daninhas resultou na obtenção de raízes do tipo comercial em maior número e com mais biomassa de matéria fresca.
\end{abstract}

Palavras-chave: controle químico, período residual, produção, Beta vulgaris L., bioensaio.

\section{ABSTRACT \\ WEED CONTROL IN TABLE BEET WITH METAMITRON AND ITS PERSISTENCE IN ULTISOL-KANDIUCULTS}

In order to study weed control efficiency and soil persistence, a field experiment was carried out in Ultisol-Kandiucult with table beet (Beta vulgaris L.) cultivar Tall Top. The treatments were: metamitron applied in pre-emergence at 2,8;3,5 and 4,2 kg.ha- ${ }^{-1}$ a.i, plus two controls, one weeded and another always with weeds, in a randomized block design with four replications. Weed control and selectivity were evaluated at 28 and 70 days and persistence in soil at 0,21, 49 and 70 days after treatments (DAA), with

( $\left.{ }^{1}\right)$ Recebido para publicação em 18 de fevereiro de 2003 e aceito em $1 .^{\circ}$ de março de 2004.

$\left({ }^{2}\right)$ Centro de Ecofisiologia e Biofísica, Instituto Agronômico (IAC), Caixa Postal 28, 13001-970 Campinas (SP). E-mail: rdeuber@iac.sp.gov.br

(3) Centro de Horticultura, IAC, Caixa Postal 28, 13001-970 Campinas (SP). E-mail: petrani@iac.sp.gov.br

$\left({ }^{4}\right)$ Mestre em Produção Vegetal, IAC. Casa da Agricultura de Santa Cruz da Conceição (SP).

$\left(^{5}\right)$ Mestre em Produção Vegetal, IAC. Bayer CropScience, Caixa Postal 921, 13140-000 Paulínia (SP). 


\begin{abstract}
bioassays using lettuce (Lactuca sativa L.) cultivar Elisa Crespa. The main weeds occuring in the trial were Eleusine indica (L.) Gaertn, Galinsoga parviflora Cav. and Coronopus dydimus (L.) Sm. Metamitron at the applied rates was apparently selective to table beets, considering the leaves. G. parviflora and C. dydimus were efficiently controlled with any of the applied rates up to 70 DAA. E. indica was well controlled until 28 DAA with all rates and until 70 DAA only with 3,5 and $4,2 \mathrm{~kg} \cdot \mathrm{ha}^{-1}$. Residual activity for 2,8 and $3,5 \mathrm{~kg}$, lasted until $70 \mathrm{DAA}$, but for 4,2 kg it was longer. Chemical weed control improved yield with an increase on table beet roots of commercial type.
\end{abstract}

Key words: chemical control, residual period, yield, Beta vulgaris L., bioassay.

\section{INTRODUÇÃO}

A beterraba, planta da família Chenopodiaceae, é originária da Europa, de elevado valor nutricional, destacando-se, entre as hortaliças, pelo seu conteúdo em vitaminas do complexo $\mathrm{B}$ e os nutrientes potássio, sódio, ferro, cobre e zinco (FerReira e TivelLi, 1990).

Segundo Camargo Filho e Mazzei (2002), no Estado de São Paulo existem, aproximadamente, 700 propriedades agrícolas, perfazendo 5.000 ha, onde são produzidas 115.000 toneladas de beterraba por ano. Ainda, segundo esses autores, ao contrário da cenoura e de outras raízes tuberosas, o mercado e o consumo "per capita" de raízes de beterraba apresentaram acréscimo substancial nas quantidades comercializadas no ETSP-CEAGESP (São Paulo - Capital). A comercialização mensal, no período de 1984 a 1991, foi de 60.975 caixas de $22 \mathrm{~kg}$ e, no de 1991 a 1994, de 80.452 caixas.

Um dos fatores determinantes para se alcançar boas produções de hortaliças, entre elas a beterraba, é o manejo adequado das plantas daninhas. Com o incremento, em anos recentes, do sistema de sucessão de cultivos, tornou-se importante o estudo da presença de resíduos de herbicidas no solo, uma vez que os ciclos dessas culturas são geralmente curtos. TRANI e PAssos (1998) recomendam a alface como uma das hortaliças em sucessão à beterraba.

Para a cultura da beterraba, há poucas opções de herbicidas destinados ao controle de plantas daninhas. Recentemente foi introduzido o metamitron, pertencente ao grupo químico das triazinonas, a ser aplicado tanto em pré- como em pósemergência precoce e é seletivo à beterraba. $\mathrm{O}$ produto é absorvido principalmente pelas raízes, mas não atua sobre as sementes das plantas daninhas. Sua ação ocorre quando se inicia o processo fotossintético inibindo o transporte de elétrons (Herbicide HaNdBOOK Committee, 2002).

O objetivo deste trabalho foi avaliar a eficácia do herbicida metamitron no manejo de plantas daninhas e sua seletividade às plantas de beterraba cv. Tall Top Wonder, bem como determinar seu período residual no solo.

\section{MATERIAL E MÉTODOS}

O experimento foi instalado a campo, no Centro Avançado de Pesquisa Tecnológica do Agronegócio de Frutas, do Instituto Agronômico, localizado no município de Jundiaí (SP), em condições usuais de cultivo da beterraba (Beta vulgaris L.) cultivar Tall Top Wonder, em Argissolo Vermelho-Amarelo, distrófico.

As análises químicas e granulométricas de amostra de solo, coletada na camada de $0-20 \mathrm{~cm}$ de profundidade, apresentaram os seguintes resultados: pH (em $\left.\mathrm{CaCl}_{2}\right): 5,1 ; 17$ g.dm ${ }^{-3}$ de M.O.; $43 \mathrm{mg} \cdot \mathrm{dm}^{-3} \mathrm{de}$ $\mathrm{P}$ (resina); 3,6 $\mathrm{mmol}_{\mathrm{c}} \cdot \mathrm{dm}^{-3}$ de K; $14 \mathrm{mmol}_{\mathrm{c}} \cdot \mathrm{dm}^{-3} \mathrm{de} \mathrm{Ca}$; $4 \mathrm{mmol}_{\mathrm{c}} \cdot \mathrm{dm}^{-3} \mathrm{de} \mathrm{Mg} ; \mathrm{H}+\mathrm{Al}: 23 \mathrm{mmol}_{\mathrm{c}} \cdot \mathrm{dm}^{-3}$ e CTC 49,4; $\mathrm{V} \%=44 \mathrm{mmol}_{\mathrm{c}} \cdot \mathrm{dm}^{-3} ; 19,2 \%$ de argila; $15,8 \%$ de silte: $47,4 \%$ de areia grossa e $17,6 \%$ de areia fina. A calagem e a adubação foram realizadas conforme as recomendações de Trani et al. (1997).

O plantio no campo foi realizado em 15/5/ 2002, utilizando-se mudas de beterraba com 30 dias de idade, provenientes de bandejas de 72 células, cultivadas em substrato Plantmax HT da Eucatex.

As parcelas mediam 1,00 m de largura por 3,00 m de comprimento, sendo divididas em duas partes de 1,50 m por $1,00 \mathrm{~m}$. Em uma das partes, as mudas de beterraba foram plantadas em quatro linhas espaçadas de 0,25 m entre linhas e de 0,10 cm entre plantas. Na outra parte da parcela nada foi plantado e destinou-se ao estudo da persistência do metamitron.

Foram realizados tratamentos fitossanitários preventivos, com mancozeb, para evitar a cercosporiose e curativos, com paration metílico, para o controle de vaquinha (Diabrotica speciosa) nas doses e freqüência de aplicação indicadas por FerreIra e Tivelli (1990).

O delineamento adotado foi o de blocos ao acaso, com quatro repetições para a cultura da beterraba. Foram estudados os efeitos de doses de metamitron, (2,8, 3,5 e 4,2 kg.ha-1 de ingrediente ativo), empregando-se a formulação comercial Goltik, contendo $70 \%$ desse composto. Além desses tratamentos, havia duas testemunhas, uma sempre capinada e outra mantida com plantas daninhas durante todo o ciclo. 
O metamitron foi aplicado em área total sobre as plantas de beterraba e pré-emergência das plantas daninhas, em toda a extensão das parcelas $\left(3,00 \mathrm{~m}^{2}\right)$, logo após o transplantio das mudas, com pulverizador costal a $\mathrm{CO}_{2}$, dotado de uma barra com dois bicos de jato plano (80.02), espaçados de 0,50 m, e consumo de calda correspondente a $400 \mathrm{~L} \cdot \mathrm{ha}^{-1}$, à pressão constante de $2,15 \mathrm{kgf.cm}{ }^{-2}$. A condição térmica do local foi adequada ao desenvolvimento da cultura, sendo necessária a irrigação suplementar por aspersão.

Para a determinação do período residual, a partir da aplicação do herbicida foram realizadas amostragens, na camada de 0 a $10 \mathrm{~cm}$ de profundidade, aos 0, 21, 49 e 70 dias DAA, nas metades das parcelas sem plantio de beterraba. Para essas análises, obedeceu-se ao delineamento de parcelas subdivididas no tempo, cada época correspondendo a uma subparcela. As amostras de terra de cada época foram destorroadas e passadas por peneira de $2 \mathrm{~mm}$ antes de serem utilizadas nos testes.

A atividade residual do metamitron no solo foi avaliada por meio de bioensaios, nos quais o desenvolvimento da planta-teste, em condições de casa-de-vegetação, indica a presença do produto aplicado.

O método de Santelman et al. (1971) foi aplicado na forma descrita por Novo et al. (1991). Como planta-teste empregou-se a alface (Lactuca sativa L.) cultivar Elisa Crespa, sendo semeadas dez sementes por vaso e desbastadas após a germinação para cinco plantas.

As plantas de alface foram cortadas rente ao solo, aos 21 dias após a semeadura, sendo avaliada a biomassa de matéria fresca da parte aérea, uma vez que a quantidade de material era muito pequena para se determinar a massa seca.

Para o estudo da relação entre o efeito de doses de metamitron e o crescimento da parte aérea, a biomassa de matéria fresca da parte aérea foi transformada em porcentagem em relação ao desenvolvimento da planta-teste do tratamento-testemunha considerado igual a $100 \%$.

As avaliações de eficiência no controle das plantas daninhas e de seletividade às plantas de beterraba do herbicida metamitron foram realizadas, nas duas linhas centrais, aos 28 e 70 DAA, por amostragem, em área correspondente a $5 \%$ da parcela. Utilizaram-se amostradores de $0,25 \times 0,25 \mathrm{~m}$ aos 28 DAA e circulares com $0,50 \mathrm{~m}$ de diâmetro aos 70 DAA. Considerou-se eficiente o tratamento que resultou em redução igual ou superior a $80 \%$ da infestação calculada em relação à testemunha sem capina.
Aos 90 DAA, foram medidas nas linhas de bordadura de cada subparcela, a altura de dez plantas. Todas as plantas das duas linhas centrais foram colhidas, separadas as raízes da parte aérea e determinadas a biomassa de matéria fresca. As raízes foram separadas por tamanho, e consideradas como 'tipo comercial' as que não apresentavam defeitos e com diâmetro médio entre 5 e $8 \mathrm{~cm}$. As raízes com diâmetros inferiores ou superiores a esses ou as que apresentavam defeitos foram consideradas como 'tipo descarte'. Após a classificação, as raízes foram contadas e pesadas. Foi, também, determinado o diâmetro médio das raízes comerciais, sendo medidas, ao acaso, dez unidades de cada parcela.

Para os dados da atividade residual do metamitron em alface, as variáveis foram submetidas à análise de variância de acordo com o método para experimentos com parcelas subdivididas no tempo (Steel e Torreie, 1980), empregando-se o teste F. O efeito de doses por época foi avaliado através de regressão polinomial. O efeito de época de amostragem (subparcela) para cada dose foi caracterizado pela equação de ajuste que melhor representou o comportamento da variável porcentagem de crescimento em relação à testemunha, sendo consideradas as equações que tinham significado biológico.

Os outros dados, quando significativos, apresentaram suas médias comparadas pelo teste de Tukey a $5 \%$ de probabilidade. Os dados em porcentagem e de número de raízes, antes de serem analisados estatisticamente, foram transformados, respectivamente, em arco seno de raiz de $\mathrm{x} / 100$ e em raiz de $\mathrm{x}$.

\section{RESULTADOS E DISCUSSÃO}

Em relação à fitotoxicidade, verificou-se que metamitron, em todas as doses aplicadas, foi, aparentemente, seletivo às plantas de beterraba, não sendo observados sintomas de intoxicação até os 70 DAA na parte aérea.

As principais espécies daninhas presentes na área experimental foram: Eleusine indica (L.) Gaertn. (capim-pé-de-galinha), Galinsoga parviflora Cav (picãobranco) e Coronopus didymus (L.) Sm. (mentruz).

As porcentagens de controle das plantas daninhas identificadas no experimento encontram-se na tabela 1 . Tanto na amostragem realizada aos 28 , quanto aos $70 \mathrm{DAA}$, picão-branco e mentruz foram totalmente controlados com quaisquer das doses aplicadas. MATALlo et al. (1991) verificaram que quando foram aplicadas doses entre 3,5 e $5,6 \mathrm{~kg} / \mathrm{ha}$ de metamitron, houve controle superior a $91 \%$ para o picão-branco. 
Tabela 1. Porcentagem de controle de picão-branco (Galinsoga parviflora Cav) - GASPA, mentruz (Coronopus didymus) - CODPI e capim-pé-de-galinha (Eleusine indica (L.) Gaertn.) - ELEIN, nas avaliações realizadas aos 28 e 70 DAA de metamitron em Jundiaí (SP), 2002

\begin{tabular}{|c|c|c|c|c|c|c|}
\hline \multirow{3}{*}{ Doses de metamitron } & \multicolumn{6}{|c|}{ Porcentagem de controle ${ }^{(1)}$} \\
\hline & \multicolumn{2}{|c|}{ GASPA } & \multicolumn{2}{|c|}{ CODPI } & \multicolumn{2}{|c|}{ ELEIN } \\
\hline & 28 dias & 70 dias & 28 dias & 70 dias & 28 dias & 70 dias \\
\hline \multicolumn{7}{|l|}{ kg.ha ${ }^{-1}$} \\
\hline 0 & $0 \mathrm{~b}$ & $0 \mathrm{~b}$ & $0 \mathrm{~b}$ & $0 \mathrm{~b}$ & $0 \mathrm{~b}$ & $0 \mathrm{c}$ \\
\hline 2,8 & $100 \mathrm{a}$ & $100 \mathrm{a}$ & $100 \mathrm{a}$ & $100 \mathrm{a}$ & $100 \mathrm{a}$ & $40 \mathrm{~b}$ \\
\hline 3,5 & $100 \mathrm{a}$ & $100 \mathrm{a}$ & $100 \mathrm{a}$ & $100 \mathrm{a}$ & $100 \mathrm{a}$ & $100 \mathrm{a}$ \\
\hline 4,2 & $100 \mathrm{a}$ & $100 \mathrm{a}$ & $100 \mathrm{a}$ & $100 \mathrm{a}$ & $100 \mathrm{a}$ & $100 \mathrm{a}$ \\
\hline
\end{tabular}

$\left({ }^{1}\right)$ Dados transformados em arco seno raiz de $\mathrm{x} / 100$ para análise estatística.

O capim-pé-de-galinha (Tabela 1), aos 28 DAA, foi totalmente controlado com quaisquer das doses de metamitron aplicadas. Entretanto, aos 70 DAA, somente com as doses de 3,5 e 4,2 kg.ha-1 observou-se controle eficiente dessa espécie. MATALLO et al. (1991) notaram que na dose de $2,8 \mathrm{~kg} / \mathrm{ha}$, o metamitron mostrou controle diferenciado, por espécie; para o picão-branco e o capim-pé-de-galinha, o controle foi, respectivamente, muito bom (superior a $81 \%$ ) e regular (acima de $41 \%$ ).

Quanto aos dados de persistência, observouse que a biomassa de matéria fresca das plantas de alface, para a dose zero, diminuiu linearmente em função do tempo (Tabela 2). Para a dose de 2,8 kg.ha ${ }^{-1}$, ao contrário, com o passar do tempo houve aumento linear na biomassa da matéria fresca em vista da degradação do produto. Para as doses de 3,5 e 4,2 $\mathrm{kg} \cdot \mathrm{ha}^{-1}$, a biomassa de matéria fresca da parte aérea, seguiu uma equação do segundo grau. A redução da massa seca na testemunha pode ser explicada pela ocorrência de elevada infestação de plantas daninhas que consumiram, gradativamente, os nutrientes disponíveis do solo.

O efeito de doses de metamitron no crescimento da alface em relação à testemunha, nas diferentes épocas de amostragens está apresentado na figura 1. Pode-se observar que para quaisquer doses, houve resposta exponencial em relação ao efeito de época para cada uma. Verificou-se que, para as doses 2,8 e 3,5 kg.ha ${ }^{-1}$, o período residual foi de 70 dias e para 4,2 kg.ha ${ }^{-1}$ foi pouco superior, ainda que não determinado (Tabela 3). Dados da Herbicide Handbook Committee (2002) ressaltam que sob condições normais de cultivo, a persistência desse produto é de quatro a seis semanas. Acredita-se que a maior persistência observada nesse experimento deve-se às temperaturas mais baixas nas condições de outono-inverno. Não foram encontrados relatos de avaliação de persistência de metamitron para as condições do Brasil. Considerando-se a dose de 3,5 kg.ha ${ }^{-1}$ suficiente para o controle de plantas daninhas em beterraba, metamitron não deverá apresentar riscos às culturas plantadas em seqüência.

Verificou-se que, nos tratamentos em que foi feita capina ou aplicado metamitron, na dose de 4,2 $\mathrm{kg} . \mathrm{ha}^{-1}$, ocorreu maior número de raízes comerciais de beterraba, quando comparados com a testemunha não capinada (Tabela 4).

O não-controle das plantas daninhas afetou a qualidade das raízes, observando-se que no tratamento não capinado ocorreu maior número de raízes tipo descarte, quando comparado aos tratamentos em que se empregou metamitron em dose acima de 3,5 $\mathrm{kg} . \mathrm{ha}^{-1}$ e a testemunha capinada. Segundo TozANi et al. (1997), quando a beterraba convive com a comunidade de plantas daninhas durante todo o ciclo, ocorre redução de $84 \%$ na produção; sugere-se que para obter a produção adequada é necessário manter a cultura no limpo até os 50 dias. $\mathrm{Na}$ avaliação do número de raízes total (tipos comercial + descarte) não se observou diferença entre os tratamentos (Tabela 4).

Quando se realizou o controle das plantas daninhas, houve aumento no diâmetro das raízes comerciais (Tabela 4). A biomassa de matéria fresca de raiz do tipo comercial foi maior no tratamento capinado e menor no não-capinado. Não houve diferença entre o tratamento capinado e as doses de 3,5 e 4,2 $\mathrm{kg}$.ha ${ }^{-1}$ de metamitron. Não houve diferença entre tratamentos quanto à massa de matéria fresca da parte aérea e de raíz do tipo descarte (Tabela 5). A biomassa de matéria fresca de raíz do tipo comercial foi maior no tratamento capinado e menor no não-capinado. Não houve diferença entre o tratamento capinado e as doses 3,5 e 4,2 kg.ha- ${ }^{-1}$ de metamitron. 


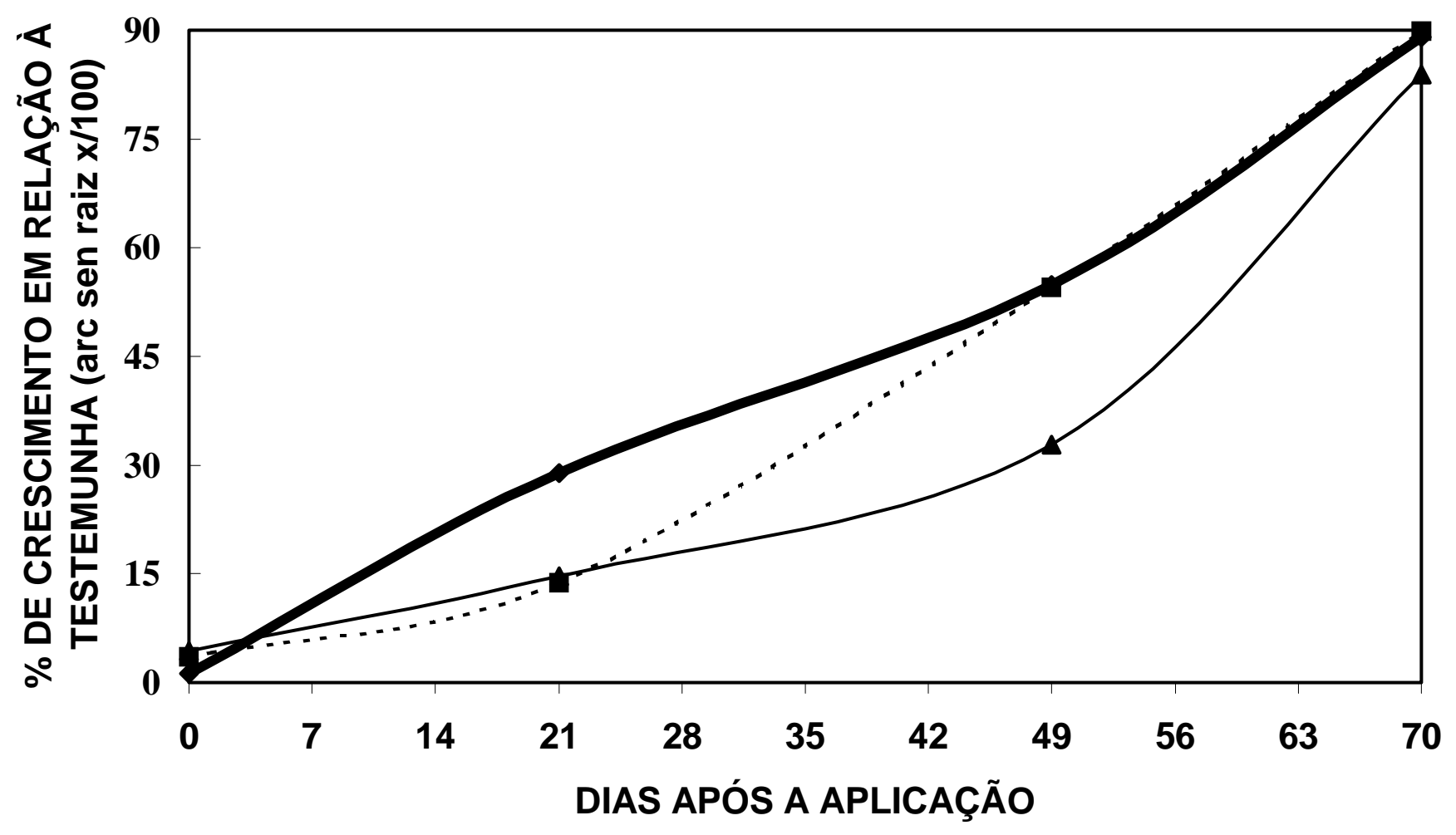

\section{$2,8 \mathrm{KG} / \mathrm{HA} \cdots-\cdot-3,5 \mathrm{KG} / \mathrm{HA} \longrightarrow 4,2 \mathrm{KG} / \mathrm{HA}$}

Figura 1. Efeito de doses de metamitron, aplicado em Argissolo, no crescimento da planta-teste (alface) em relação à testemunha nas diferentes épocas.

Tabela 2. Efeito de doses de metamitron, aplicado em Argissolo, na biomassa da matéria fresca de plantas de alface para as diferentes épocas de amostragens de solo para bioensaio, em Jundiaí (SP), 2002

\begin{tabular}{|c|c|c|c|c|}
\hline \multirow[t]{2}{*}{ Épocas de amostragem } & \multicolumn{4}{|c|}{$\begin{array}{c}\text { Biomassa da matéria fresca das plantas de alface (mg.planta } 1) \\
\text { nas diferentes doses de metamitron }\end{array}$} \\
\hline & 0 kg.ha-1 & $2,8 \mathrm{~kg} \cdot \mathrm{ha}^{-1}$ & 3,5 kg.ha- ${ }^{-1}$ & $4,2 \mathrm{~kg} \cdot \mathrm{ha}^{-1}$ \\
\hline 0 dias & 150,0 & 0,0 & 0,0 & 0,0 \\
\hline 21 dias & 145,0 & 13,5 & 10,5 & 0,0 \\
\hline 49 dias & 77,5 & 63,3 & 50,5 & 34,2 \\
\hline 70 dias & 92,5 & 90,8 & 85,0 & 90,0 \\
\hline$a^{1}$ & 152,67241 & $-5,81897$ & $-0,34483$ & 0,30172 \\
\hline $\mathrm{b}$ & $-1,04064$ & 1,36269 & 0,21053 & $-0,61917$ \\
\hline c & - & - & 0,016521 & 0,02709 \\
\hline $\mathrm{r}^{2} / \mathrm{R}^{2} 2$ & 87,38 & 98,82 & 99,99 & 99,99 \\
\hline
\end{tabular}

$\left({ }^{1}\right)$ Coeficientes das equações de regressão linear (a e b) ou quadrática ( $a, b$ e c) respectivamente.

$\left({ }^{2}\right)$ Coeficientes de determinação linear e quadrático respectivamente. 
Tabela 3. Equações de ajuste referentes ao efeito de época de amostragem para cada dose de metamitron quanto à porcentagem de crescimento em relação à testemunha

\begin{tabular}{lcr}
\hline Dose de metamitron & Equação de ajuste $^{(1)}$ & Período residual \\
\hline $\mathrm{kg} \cdot \mathrm{ha}^{-1}$ & & dias \\
2,8 & $1 /\left(0,7673+-0,6770 \mathrm{x}^{0,0260}\right)$ & 70 \\
3,5 & $112,8853 /\left(1+30,2334 \exp ^{(-0,0682 \times)}\right)$ & 70 \\
4,2 & $1 /\left(0,2267-0,0735 \mathrm{x}^{0,2524}\right)$ & $>70$ \\
\hline
\end{tabular}

$\left({ }^{1}\right)$ Os dados foram transformados em arco seno de raiz de $x / 100$.

Tabela 4. Efeitos dos tratamentos no número e no diâmetro de raízes de beterraba no experimento desenvolvido em Jundiaí (SP).

\begin{tabular}{|c|c|c|c|c|}
\hline \multirow{2}{*}{ Tratamentos } & \multicolumn{3}{|c|}{ Número de raízes ${ }^{(1)}$} & \multirow{2}{*}{$\begin{array}{c}\text { Diâmetro de raiz } \\
\text { comercial }\end{array}$} \\
\hline & Comercial & Descarte & Total & \\
\hline & \multicolumn{3}{|c|}{$-\mathrm{n}^{\circ} / 1,5 \mathrm{~m}^{2}$} & $\mathrm{~cm}$ \\
\hline Testemunha capinada & $30,68 \mathrm{a}$ & $13,93 \mathrm{c}$ & $44,61 \mathrm{a}$ & $6,77 \mathrm{a}$ \\
\hline Test. não capinada & $20,04 \mathrm{~b}$ & 32,97 a & 53,01 a & $5,83 \mathrm{~b}$ \\
\hline 2,8 kg.ha ${ }^{-1}$ de metamitron & $27,73 \mathrm{ab}$ & $24,17 \mathrm{ab}$ & 51,90 a & $6,72 \mathrm{a}$ \\
\hline 3,5 kg.ha ${ }^{-1}$ de metamitron & $30,20 \mathrm{ab}$ & $19,52 \mathrm{bc}$ & 49,72 a & $6,71 \mathrm{a}$ \\
\hline 4,2 kg.ha ${ }^{-1}$ de metamitron & 33,21 a & $17,46 \mathrm{bc}$ & $50,67 \mathrm{a}$ & $6,59 \mathrm{ab}$ \\
\hline C.V. $(\%)$ & 8,55 & 8,95 & 4,90 & 5,99 \\
\hline DMS 5\% & 1,02 & 0,93 & 0,78 & 0,88 \\
\hline
\end{tabular}

$\left.{ }^{1}\right)$ Dados transformados em raiz de x para análise estatística, sendo apresentados os dados originais.

Tabela 5. Efeito dos tratamentos nas biomassas de matéria frescas (BMF) de raízes e da parte aérea e na altura média de plantas de beterraba no experimento realizado em Jundiaí (SP)

\begin{tabular}{|c|c|c|c|c|c|}
\hline \multirow{2}{*}{ Tratamentos } & \multicolumn{3}{|c|}{ BMF de raiz } & \multirow{2}{*}{$\begin{array}{c}\text { BMF } \\
\text { Parte aérea }\end{array}$} & \multirow{2}{*}{$\begin{array}{c}\text { Altura média } \\
\text { de plantas }\end{array}$} \\
\hline & Comercial & Descarte & Total & & \\
\hline & \multicolumn{4}{|c|}{ g. $1,5 \mathrm{~m}^{-2}$} & $\mathrm{~cm}$ \\
\hline Testemunha capinada & $3.772 \mathrm{a}$ & $460 \mathrm{a}$ & $4.232 \mathrm{a}$ & $1.839,25 \mathrm{a}$ & 38,03 a \\
\hline Test. Não capinada & $1.018 \mathrm{c}$ & 889 a & $1.907 \mathrm{~b}$ & $1.221,63 \mathrm{a}$ & $38,55 \mathrm{a}$ \\
\hline 2,8 kg.ha ${ }^{-1}$ de metamitron & $2.505 \mathrm{~b}$ & $808 \mathrm{a}$ & $3.313 \mathrm{a}$ & $2.020,75 \mathrm{a}$ & $37,90 \mathrm{a}$ \\
\hline $3,5 \mathrm{~kg} \cdot \mathrm{ha}^{-1}$ de metamitron & $2.980 \mathrm{ab}$ & $780 \mathrm{a}$ & $3.760 \mathrm{a}$ & $2.047,53 \mathrm{a}$ & $39,40 \mathrm{a}$ \\
\hline $4,2 \mathrm{~kg} \cdot \mathrm{ha}^{-1}$ de metamitron & $2.997 \mathrm{ab}$ & $724 \mathrm{a}$ & $3.721 \mathrm{a}$ & $2.168,50 \mathrm{a}$ & $35,73 \mathrm{a}$ \\
\hline C.V. $(\%)$ & 19,60 & 39,78 & 17,93 & 27,60 & 10,65 \\
\hline DMS 5\% & $1.173,26$ & 657 & 1369 & $1.157,31$ & 9,10 \\
\hline
\end{tabular}

Obs. Dados transformados em raiz de x para análise estatística, sendo apresentados os dados originais. Valores nas colunas, seguidos de letras iguais não diferem entre si a $5 \%$ pelo teste de Tukey. 
A produção de raízes do tipo comercial no tratamento com 2,8 kg.ha ${ }^{-1}$ de metamitron foi inferior ao da testemunha capinada devido à infestação do capim-pé-de-galinha (Tabela 1). Em relação à biomassa da matéria fresca total de raízes (tipos comercial + descarte), verificou-se que apenas a testemunha não capinada apresentou resultado inferior ao da capinada (Tabela 5). Segundo Filgueira (2000), a produtividade da beterraba situa-se entre 2,0 e 3,5 kg. $\mathrm{m}^{-2}$, verificando-se que todos os tratamentos, exceto a testemunha não capinada, apresentaram produção de raízes de beterraba com qualidade comercial.

\section{CONCLUSÕES}

1. Metamitron aplicado nas diversas doses não causou fitotoxicidade à cultura da beterraba.

2. O picão-branco e o mentruz foram eficientemente controlados com quaisquer das doses de metamitron. Aos 28 dias, o capim-pé-de-galinha foi controlado com quaisquer das doses de metamitron aplicada; aos 70 DAA, somente com doses de 3,5 e $4,2 \mathrm{~kg} \cdot \mathrm{ha}^{-1}$ obteve-se controle eficiente.

3. O período residual de metamitron para as doses de 2,8 e 3,5 kg.ha-1 foi de 70 dias e para 4,2 kg.ha ${ }^{-1}$ foi superior a esse período.

4. O controle de plantas daninhas resultou em maior número e maior quantidade de biomassa de matéria fresca de raízes do tipo comercial.

\section{REFERÊNCIAS}

CAMARGO FILHO, W.P.; MAZZEI, A.R. Mercado de beterraba em São Paulo. Informações Econômicas, São Paulo, v.32, n.4, p.56-58, 2002.

FERREIRA, M.D.; TIVELLI, S.W. Cultura da beterraba: recomendações gerais. 3.ed. Guaxupé: COOXUPÉ, 1990. 14p. (Boletim Técnico Olericultura, 2).
FILGUEIRA, F.A.R. Chenopodiaceae - beterraba e hortaliças herbáceas. In: FILGUEIRA, F.A.R. Novo Manual de Olericultura: agroecologia moderna e comercialização de hortaliças. Viçosa: UFV, 2000. p.362-366.

HERBICIDE HANDBOOK COMMITTEE. Herbicide Handbook. 8.ed. Lawrence: Weed Science Society of America, 2002. p.292.

MATALLO, M.B.; SALVO, S.; BLANCO, H.G. Seletividade e eficiência do metamitron sobre plantas daninhas na cultura da beterraba hortícola. In: CONGRESSO BRASILEIRO DE HERBICIDAS E PLANTAS DANINHAS, 18., 1991, Brasília. Resumos... Brasília: SBHED, 1991. p.100.

NOVO, M.C.S.S.; LOPES, E.S.; ORTOLANI, M.C.A. Levantamento da nodulação, persistência de herbicidas e isolamento de Bradyrhizobium spp. de áreas com rotação cana-de-açúcar/ amendoim. Revista de Microbiologia, São Paulo, v.22, p.6065, 1991.

STEEL, R.G.D. ; TORRIE, J.H. Analysis of variance: IV. Splitplot designs and analysis. In: STEEL, R.G.D.; TORRIE, J.H. (Eds.). Principles and Procedures of Statistics. 2.ed. New York: McGraw Hill, 1980. cap.16, p.377-400.

TOZANI, R.; SOUZA, C.L.M.; MORAIS, V.; COELHO, R.G.; LOPES, C.A.; JÚNIOR, O.F.O. Interferência de plantas daninhas nas culturas da cenoura (Daucus carota) e beterraba (Beta vulgaris). In: CONGRESSO BRASILEIRO DE CIÊNCIA DAS PLANTAS DANINHAS, 21., 1991, Caxambu. Resumos... Viçosa: SBCPD, 1997. p.390.

TRANI, P.E. ; PASSOS, F.A. Beterraba. In: FAHL, J.I. et al. (Eds.). Instruções agrícolas para as principais culturas econômicas. 6.ed. Campinas: Instituto Agronômico, 1998. p. 184-185. (Boletim Técnico, 200)

TRANI, P.E.; PASSOS, F.A.; TAVARES, M.; AZEVEDO FILHO, J.A. Beterraba, cenoura, nabo, rabanete e salsa. In: RAIJ, B.; CANTARELLA, H.; QUAGGIO, J.A.; FURLANI, A.M. (Eds.). Recomendações de adubação e calagem para o Estado de São Paulo. 2.ed. Campinas: Instituto Agronômico \& Fundação IAC, 1997. p.174. (Boletim Técnico, 100). 